\title{
Comparative and qualitative study of fruit leather from wild and cultivated apricot (Prunus armeniaca L.) grown under agro-climatic condition of Rawalakot Azad Kashmir Pakistan
}

\author{
Zamird Bashir ${ }^{1}$, Imtiaz Hussain ${ }^{1}$, Nadra Khan ${ }^{2 *}$, Saiqa Bashir ${ }^{1}$, Nosheen \\ Bashir $^{3}$, Nagina Rafique ${ }^{1}$ and Shafiq Ur Rehman ${ }^{4}$ \\ 1. Department of Food Science and Technology, Faculty of Agriculture, University of the Poonch Rawalakot, \\ 12350, AJK-Pakistan \\ 2. Department of Horticulture, Faculty of Agriculture, University of the Poonch Rawalakot, 12350, AJK-Pakistan \\ 3. Department of Veterinary, the University of Poonch Rawalakot, 12350, AJK-Pakistan \\ 4. Department of Plant breeding and genetics, Faculty of Agriculture Sciences, University of the Poonch, \\ Rawalakot-Pakistan \\ *Corresponding author's email: nadrakhan.upr@gmail.com
}

\section{Citation}

Zamird Bashir, Imtiaz Hussain, Nadra Khan, Saiqa Bashir, Nosheen Bashir, Nagina Rafique and Shafiq Ur Rehman. Comparative and qualitative study of fruit leather from wild and cultivated apricot (Prunus armeniaca L.) grown under agro-climatic condition of Rawalakot Azad Kashmir Pakistan. Pure and Applied Biology. Vol. 9, Issue 4, pp2279-2284. http://dx.doi.org/10.19045/bspab.2020.90242

\begin{tabular}{llll}
\hline \hline Received: 13/03/2020 & Revised: 16/06/2020 & Accepted: 25/06/2020 & Online First: 08/07/2020 \\
\hline
\end{tabular}

\section{Abstract}

There is an abundant apricot fruit production in Rawalakot Azad Jammu and Kashmir, Pakistan. Unfortunately due to improper post-harvest management practices, more than $50 \%$ of post-harvest losses have been recorded annually. The seasonal fruit production offers an excellent opportunity for the development of novel fruit products. The current study was planned to develop the pulp products of apricot with an objective to minimize the post-harvest losses of local apricot and to evaluate the physico-chemical and sensory properties of fruit leather and pulp. Vitamin C, TSS and acidity were evaluated by the AOAC method. The quality traits, sensory evolution and storage stability were assessed by the interval of 15 days. The highest $79 \%$ moisture was found in cultivated fruit pulp (CFP). Maximum (7.3) $\mathrm{pH}$ was found in cultivated fruit leather (CFL). In the case of total soluble solids, the highest $(23.3 \%)$ was seen in cultivated fruit leather. Maximum $(14.01 \mathrm{mg} / 100 \mathrm{~g}$ and $0.21 \%)$ vitamin $\mathrm{C}$ and acidity were found in wild fruit pulp. The highest $(33.55 \%)$ sugar content was seen in cultivated fruit leather. As for as concern with acceptability, cultivated fruit pulp had maximum (6.81) acceptability. Based on these findings, apricot fruit leather and pulp contained a good amount of sugar, vitamin $\mathrm{C}$ and TSS having high acceptability. The value addition, apricot fruit product could play an important role to minimize postharvest losses annually as well as improve the nutritional and economic status of the community and also boost up the economy of the country through export share.

Keywords: Apricot; Fruit leather; Product development; Value addition 


\section{Introduction}

Fruit leather is dehydrated (fruit-based) products having chewy nature, good in taste and generally made by pouring pureed fruit on to a flat surface. After drying the fruit is pulled out from the surface, and then rolled and the resultant product is named as "leather", whereas pureed fruit and subsequent drying gives the shiny texture to the leather. It is thin layer pureed, dried in oven or dehydrator in the form of sheet. It is taken as snacks or candy and offered as elastic streaks sheet. Due to its shiny texture and origin, the Persian Empire named the fruit bar or fruit roll [1]. Some of the other prominent names are fruit rolls fruit bars, Pestil, Bastegh, Pastegh, deenandor taffies in various parts of the world [2]. Fruit leather has its importance because of its novelty, appealing appearance (texture) and no need for refrigeration for the longer shelf life [3].

It serves as delicious, healthy and nutritious high-energy snacks for backpackers, campers and vigorous humans. The dried fruit and snacks are healthier than the confectionaries. In addition, fruit leathers can also be made by mixing juices of other fruits and the use of low sugar content with mixed fruit flavors. Fruit leather is comparatively lightweight, easy to prepare. Easy technique used to utilize surplus fruit in the form of canned fruit and over-ripe fresh fruits [4]. For diabetic patients (adult or child), more healthy choices is fruit leather, snacks or desserts [5].There are various types of fruit leathers prepared from different fruits and combinations of fruits such as apricots, apples, grapes, berries, bananas, pineapples, oranges, pears, peaches, plums, melons, and most tropical fruits, chiku, papaya, mango and jack fruit [6].

Fresh apricot (Prunus armeniaca L.) is highly perishable. It is the rich source of carbohydrates (glucose, fructose, and sucrose), malic acid, citric acid, sorbitol, minerals (phosphorus, iron) and vitamins. The production of apricot in Azad Kashmir is
24658 tones and annual production of fresh apricot fruit in Pakistan has been recorded as 192, 500 tons in 2018-19 whereas the total world apricot production during 2018-19 was 4,038,520 tons [7].

Annually post-harvest losses of fruits are more than $30 \%$ in the world, while postharvest losses of apricot are more than 50\% in Azad Jammu Kashmir. The apricot consumed as fresh and processed food, such as juice, jam, jellies, canned dried and marmalades also used in the transfer form of leather fruit.

Keeping in view the significance of apricot in the region, the present research was carried to minimize post-harvest losses of abundant seasonal produce and development of fruit fruit product (fruit leather) through utilization of apricot by value addition. In addition evaluation of the nutritional composition of apricot fruit leather during the storage for monitoring shelf life and acceptability of the product.

\section{Materials and methods}

This research work was carried out in the laboratory of the Department of Food Science and Technology, Faculty of Agriculture, The University of Poonch, Rawalakot Azad Kashmir. The cultivated and wild ecotypes of apricot at optimum maturity were selected and then raw material was subjected to physico-chemical analysis to evaluate their quality parameters. Then the product apricot leather was developed by following the steps described herein.

Sorting, washing, pulp formulation, cooking, pouring, drying and then wrapping into the paper. To assess the physico-chemical analysis, quality and stability of apricot fruit leather as follows. The $\mathrm{pH}$ of all samples was determined using digital $\mathrm{pH}$ meter (Model \# 151) as described in [8]. Moisture content was evaluated by the following method of [9]. Total soluble solids (TSS), were determined by using digital Refractometer [Model \# RA-620/600] by following methods 
of [10]. Assessment of vitamin $\mathrm{C}$ was done according to the method described by [11]. Acidity was determined through the method followed by [11]. Total Sugars were estimated by [12]. Sensory evaluation was done by the Hedonic scale system. All the samples were enclosed in packaging material and checked at the interval of 20 days during storage period of 4 months to check storage stability/shelf life.

\section{Statistical analysis}

The statistical analysis was executed by using the Design-Expert software [13]. Level of significance was tested at $(\mathrm{P}<0.05)$.

\section{Results and discussion}

\section{Pysico-chemical analysis}

The physico-chemical analysis showed that there was a significant difference $(\mathrm{P}<0.05)$ between all set of parameters. The moisture content of the apricot leather and pulp is dependant on the drying temperature. The drying temperature was kept $50{ }^{0} \mathrm{C}$ to $55{ }^{\circ} \mathrm{C}$ and then $65{ }^{0} \mathrm{C}$. Highest $79 \%$ moisture content was observed in cultivated fruit leather (CFP) while in case of leather, wild fruit leather (WFL) showed highest (18\%) moisture content. The highest $7.3 \mathrm{pH}$ was depicted in cultivated fruit leather whereas among pulps of both ecotypes cultivated fruit pulp showed maximum (4.55) pH (Table 1). Total soluble solids (TSS) percentage was illustrated in (Table 2), highest $(23.30 \%)$ TSS was seen in cultivated fruit leather (CFL) whereas wild fruit pulp showed maximum $(8.21 \%)$ total soluble solids among both type of apricot. Dry matter /TSS percentage is different might be due to different location have different climatic conditions, soil and temperature. The plants which have more leaf area definitely have more dry matter. These findings are also confirmed by [14]. Data concerning Vitamin $\mathrm{C}$ content both ecotypes showed same results (14.98 mg/100g) for wild fruit leather and cultivated fruit leather while wild fruit pulp showed highest $(14.01 \mathrm{mg} / 100 \mathrm{~g})$ vitamin $\mathrm{C}$. In case of acidity wild and cultivated fruit leather showed same percentage of acidity $(0.23 \%)$ whereas wild fruit pulp showed highest $(0.21 \%)$ acidity as compare to cultivated fruit pulp. Data concerning sugar content, cultivated fruit leather showed highest $(33.55 \%)$ sugar content compare to wild fruit leather while wild fruit pulp showed maxiumum (13.0\%) sugar content as compare to cultivated one as shown in (Table $1)$.

Table 1. Analysis of fruit pulp and fruit leather of wild and cultivated apricot

\begin{tabular}{|c|c|c|c|c|}
\hline Variables & WFP mg100g & WFL gm100g & CFP gm100g & CFL gm100g \\
\hline Moisture (\%) & 78 & 18 & 79 & 16 \\
\hline pH & 4.05 & 7.0 & 4.55 & 7.3 \\
\hline TSS (\%) & 8.21 & 20.23 & 8.01 & 23.30 \\
\hline Vitamin C (mg/100g) & 14.01 & 14.98 & 13.77 & 14.98 \\
\hline Acidity (\%) & 0.21 & 0.23 & 0.18 & 0.23 \\
\hline Sugar (\%) & 13.0 & 23.04 & 12.4 & 33.55 \\
\hline
\end{tabular}

Wild fruit pulp (WFP), wild fruit leather (WFL), cultivated fruit pulp (CFP) and cultivated fruit leather (CFL)

Table 2. Analysis of variance of fruit pulp and fruit leather of wild and cultivated apricot

\begin{tabular}{|c|c|c|c|c|c|}
\hline Variables & Mean & SD & Variance & Minimum & Maximum \\
\hline Moisture (\%) & 65.200 & 27.526 & 757.70 & 16.000 & 79.000 \\
\hline PH & 5.0040 & 1.3054 & 1.7040 & 4.0500 & 7.3000 \\
\hline Sugar (\%) & 16.970 & 9.2720 & 85.970 & 12.400 & 33.550 \\
\hline TSS (\%) & 8.1675 & 0.1053 & 0.0111 & 8.0100 & 8.2300 \\
\hline VIT C (mg/100g) & 14.324 & 0.6048 & 0.3658 & 13.770 & 14.980 \\
\hline Acidity (\%) & 0.2080 & 0.2080 & 5.200 & 0.1800 & 0.2300 \\
\hline
\end{tabular}




\section{Sensory evaluation}

The results of sensory evaluation showed that all the parameters of end product was quite good collectively color, flavor and taste given good mouth feel and having more acceptable taste in fruit leather of both types, results depicted that few parameters (taste color and fructose) lacking in wild type fruit leather and few in cultivated type.

Data concerning color highest (7.66) was seen in cultivated fruit leather (CFL) whereas wild fruit pulp (WFP) showed maximum (7.52) color. Color changes in fruit ripening are of great importance, it is related to the conversion of starch to sugar that is necessary for its sweetening and for development of other desirable traits [15]. Color of wild type fruit leather was dark brown in appearance as compared to the cultivated one. The deep brown color might be due to the presence of high acid content in the wild type apricot fruit leather. The deep brown color was seen in the end product might be due to acid content reacts with sugar and form the millard reaction during cooking [16].

The results of flavor were significant. The data showed that the flavor of cultivated type apricot fruit leather (CFL) and cultivated fruit pulp (CFP) attained maxiumum (6.01 and 6.2) score as compared to wild type fruit leather because the cultivated type fruit leather had higher sugar content and having more delicious taste than the wild type leather. All these factors combine to make acceptable flavor of cultivated type fruit leather. Sour taste of wild type was due to presence of more acid contents (ascorbic acid).

Data concerning taste among both types of leather, wild fruit leather (WFL)and wild fruit pulp (WFP) found maximum (6.9 and 6.22) score as compare to cultivated one. However the taste acceptance of both types had been acceptable among the people, might be due to the preferences and choice according to taste bud.

The data concerning overall acceptance was significant among the both type of fruit leather presented in (Table 3) whereas its analysis of variance given in (Table 4). The acceptance of cultivated pulp and leather was highest (6.81 and 6.74). Lowest (5.09 and $5.85)$ acceptance was seen for wild pulp and leather. Overall acceptance for cultivated fruit leather was high due its sweet taste and appealing appearance.

Table 3. Analysis of sensory evolution of pulp and fruit leather of apricot

\begin{tabular}{|c|c|c|c|c|}
\hline Parameters & WFP & WFL & CFP & CFL \\
\hline Colour & 7.52 & 7.61 & 6.6 & 7.66 \\
\hline Flavors & 5.81 & 5.45 & 6.2 & 6.01 \\
\hline Taste & 6.22 & 6.9 & 5.4 & 5.88 \\
\hline Acceptance & 5.09 & 5.85 & 6.81 & 6.74 \\
\hline
\end{tabular}

Wild fruit pulp (WFP), wild fruit leather (WFL), cultivated fruit pulp (CFP) and cultivated fruit leather (CFL)

Table 4. Analysis of variance of sensory evolution of pulp and fruit leather of apricot

\begin{tabular}{|c|c|c|c|c|c|}
\hline Variables & Mean & SD & Variance & Minimum & Maximum \\
\hline Color & 7.1180 & 0.6724 & 0.4521 & 6.2000 & 7.6600 \\
\hline Flavor & 5.8340 & 0.2876 & 0.0827 & 5.4500 & 6.2000 \\
\hline Taste & 5.9400 & 0.6528 & 0.4262 & 5.3000 & 6.9000 \\
\hline Acceptability & 5.5820 & 0.3645 & 0.1329 & 5.2000 & 5.9900 \\
\hline
\end{tabular}

Storage stability of fruit leather per day

The data presented in (Table 5\& 6) for storage stability of fruit leather day from 0 to
120 days. The $\mathrm{pH}$ at zero-day was 4.01 and at the 120 days (4.83) was noted, the $\mathrm{pH}$ gradually increased day by day might be due 
to loss of water contents during storage. The total soluble solids were highest $(9.8 \%)$ at the initial stage and lowest $(7.44 \%)$ at the termination of the experiment. There was a gradual decrease in TSS content of fruit leather was observed. However, the vitamin $\mathrm{C}$ content of the apricot fruit leather was reported highest $(14.32 \mathrm{mg} / 100 \mathrm{mg})$ at zeroday and lowest $(7.71 \mathrm{mg} / 100 \mathrm{mg})$ was observed at 120 days, the decrease in ascorbic acid might be due to its sensitivity to heat and fluctuation of temperature during storage. Highest acidity $0.66 \%$ was seen at zero-day whereas lowest $0.46 \%$ was observed at 120 days. The sugar content of the fruit leather during the storage of 120 days showed $33 \%$ at zero days while it was decreased to $28 \%$ at 120 days. The results were significant for all the parameters, almost all the parameters of apricot fruit leather showed a gradual decreased during the four-month storage stability expect the $\mathrm{pH}$. A decrease in nutrient content might be due to the slow removal of water content in leather fruit during the storage period. The reults of all the set of parameters showed the minor differences among the zero days to 120 day. Findings were similar to [17]. Overall the acceptability of the apricot leather was excellent till the end of its storage period.

Table 5. Analysis of storage stability of cultivated fruit leather/day

\begin{tabular}{|c|c|c|c|c|c|c|c|c|c|}
\hline \multirow{2}{*}{ Variables } & \multicolumn{10}{|c|}{ Days } \\
\cline { 2 - 11 } & $\mathbf{0 0}$ & $\mathbf{1 5}$ & $\mathbf{3 0}$ & $\mathbf{4 5}$ & $\mathbf{6 0}$ & $\mathbf{7 5}$ & $\mathbf{9 0}$ & $\mathbf{1 0 5}$ & $\mathbf{1 2 0}$ \\
\hline PH & 4.01 & 4.18 & 4.22 & 4.23 & 4.50 & 4.80 & 4.81 & 4.84 & 4.83 \\
\hline TSS (\%) & 9.8 & 9.6 & 9.5 & 9.3 & 8.86 & 8.55 & 8.81 & 7.5 & 7.44 \\
\hline Vitamin C (mg/100g) & 14.32 & 12.02 & 11.1 & 10.7 & 10.0 & 9.5 & 8.9 & 7.75 & 7.71 \\
\hline Acidity (\%) & 0.66 & 0.66 & 0.64 & 0.60 & 0.56 & 0.51 & 0.49 & 0.47 & 0.46 \\
\hline Sugar (\%) & 33 & 32 & 32 & 31 & 31 & 30 & 18 & 28 & 28 \\
\hline
\end{tabular}

Table 6. Analysis of variance of storage stability of cultivated fruit leather

\begin{tabular}{|c|c|c|c|c|c|}
\hline Variables & Mean & SD & Variance & Minimum & Maximum \\
\hline Moisture (\%) & 65.200 & 27.526 & 757.70 & 16.000 & 79.000 \\
\hline PH & 4.8767 & 1.3209 & 1.7448 & 4.0100 & 8.3000 \\
\hline Vit C (mg/100g) & 9.8113 & 2.3560 & 5.5509 & 7.0000 & 14.320 \\
\hline TSS (\%) & 8.8178 & 0.8648 & 0.7479 & 7.4400 & 9.8000 \\
\hline Acidity (\%) & 0.5644 & 0.0882 & 7.778 & 0.4600 & 0.7000 \\
\hline Sugar (\%) & 16.111 & 4.5399 & 20.611 & 10.000 & 25.000 \\
\hline
\end{tabular}

\section{Conclusion}

Fruit leathers serve as delicious, healthy and nutritious high-energy snacks as compare to confectionaries. It is being marketed as luxurious healthy food products all over the world. Manufacturing of fruit bar with native fruits could minimize the postharvest losses. Moreover the developed items having high qualities, such as good texture, flavor and appearance with longer shelf life. Nutritional data on fruit bar will be valuable for the nutritional education of the people as a means to improve the dietetic as well as economic status of population and country through export share.

\section{Authors' contributions}

Conceived and designed the experiments: I Hussain \& $N$ Khan, Performed the experiments: Z Bashir, Analyzed the data: N Rafique \& N Khan, Contributed reagents/ materials/ analysis tools: S Bashir, N Bashir \& SU Rehman, Wrote the paper: Z Bashir.

\section{Acknowledgment}

The writer wants to thanks the Laboratory of Food Science and Technology, University of Poonch Rawalakot Azad Kashmir for 
collaboration, financing and technical support to conduct this experiment.

\section{References}

1. Torleya PJ, Boerb D, Bhandaria BR, Kasapisc S, Shrinivasc P \& Jiangc B (2008). Application of the synthetic polymer approach to the glass transition of fruit leathers. J Food Engine 86: 243 250.

2. Kendall P \& Sofos J (2003). Leathers and Jerkies Food and Nutrition Series leather (pistil). Department of Food Engineering, Engineering Faculty, University. Leather from roselle (Hibiscus sabdariffa L.) by-product. Asian J Food and Agro-Industry 1: 9061040.

3. Quintero NA, Demarchi SM, Massolo JF, Rodoni LM \& Giner SA (2012). Evaluation of quality during storage of apple leather. LWT-Food Sci Tech 47(2): 485-492.

4. Susan RMS (2012). Drying of fruit leathers. Sciences. University of Florida. J Food Sci \& Agric 8: 503-506.

5. Shafi ISN, Ahmad N, Abidin MZ, Hani NM \& Ismailic N (2013). Optimization of hydrocolloids and maltodextrin addition on roselle-based fruit leather using two-level full factrol design. Inter J Biosci Biochem \& Bioinform 3: 4-8.

6. Ashay OA, Babalola SO, Babalola AO, Aina JO \& Fasoyiro SB (2012). Chemical and organoleptic characterization of papaya and guava leather. Nigeria J Agric Sci 1: 50-5.

7. Anonomyus (2013). Pakistan Economics Survey of Pakistan, Ministry of Finance. Advisor Wing Islamabad, 51: 250-253.

8. AOAC (1990). Official Methods of Analysis. Association of official Analytical Chemists, Gaithersburg, Maryland, USA.
9. AOAC (1991). Official Methods of Analysis. Association of official Analytical Chemists, Gaithersburg, Maryland, USA.

10. AOAC (2000). Official Methods of Analysis. Association of official Analytical Chemists, Gaithersburg, Maryland, USA.

11. AOAC (1997). Official Methods of Analysis. Association of official Analytical Chemists, Gaithersburg, Maryland, USA.

12. Awan A J (2002). Food analysis manual $2^{\text {nd }}$ edition.

13. Steel RGD, Torrie \& Dicky DA (1997). Principal and procedures of statistics. A Biometrical Approaches $3^{\text {rd }}$ Edition. MeGraw Hill Book Co. Inc. New York, pp 400-428.

14. Mukisa IM, Okilya SA \& Kaaya N (2010). Effect of solar drying on the quality and acceptability of jack fruit leather. Inter J Food Sci 9(1): 101-111.

15. Huang $X \&$ Hsieh FH (2005). Physical properties, sensory attributes, and consumer preference of pear fruit leather. J Food Sci 70(30): 177-186.

16. Okilya SI, Mukisa M \& Kaaya AN (2000). Effect of solar drying on the quality optimization of hydrocolloids and maltodextrin addition on rosellebased fruit leather using two-Level full factrol design. Inter J Biosci Biochem \& Bioinfo 3: 4-8.

17. Lemuel M. Diamante, Xue Bai, and Janette Busch (2014). Fruit Leathers: Method of Preparation and Effect of Different Conditions on Qualities. Department of Wine, journal Food and Molecular Biosciences, Lincoln University, 7647, New Zealand, 13: 9890. 